\title{
JUDICIALIZAÇÃO DA POLÍTICA: CONTORNOS E TEORIAS- CAMINHOS RUMO A POSIÇÕES DIALOGADAS
}

\section{JUDICIALIZATION OF POLITICS: CONTOURS AND THEORIES- PATHS TO DIALOGUE}

\author{
${ }^{1}$ Melanie Claire Fonseca Mendoza
}

\section{RESUMO}

A judicialização da política, dependendo das circunstancias conjunturais, pode representar um perigo para a estabilidade do Estado Democrático de Direito. O objetivo deste trabalho é identificar essa prática, cada vez mais freqüente de intervençāo do Judiciário na política, realizando uma aproximação analítica de suas bases teóricas. Essa analise pretende contribuir para a construçāo de caminhos para uma relação dialógica entre os Poderes. Para alcançar o objetivo realizamos uma revisāo crítica da literatura e analisamos alguns posicionamentos da jurisprudência.

Palavras-chave: judicialização da política; teorias; diálogos institucionais; Estado Democrático de Direito; Separação dos Poderes.

\begin{abstract}
The judicialization of politics, depending on the conjunctures situations, may be a danger to the stability of the Democratic State of Law. The aim of this paper is identify this practice, more and more frequent, of intervention of the judiciary in politics, carrying out an analytical approach of its theoretical bases. This analysis intends to contribute to the construction of the ways for a dialogical relationship between the Powers. For this, we perform a critical review of the literature and analyze some jurisprudential positions.
\end{abstract}

Keyword: judicialization of politics; theories; institutional dialogue; Democratic State of Law; Separation of Powers.

\footnotetext{
${ }^{1}$ Doutoranda em Direito Público pela Universidade de Sevilha, (Espanha). Advogada e Professora do Curso de Direito da Universidade Estadual da Paraíba - Campina Grande, (Brasil). E-mail: melfonmen@gmail.com
} 


\section{PALAVRAS INTRODUTÓRIAS}

Ao longo da história, política e direito sempre tiveram uma relação marcada por amor e ódio, aproximação e desencontro. O jurídico e o político tiveram suas concepções marcadas por constantes e profundas transformações. Seus objetos de estudo, metodologia e objetivos em muitos momentos tiveram suas fronteiras marcadas por zonas comuns de interseção, discussão e diálogo. Talvez seja este caminho, o do diálogo, que mereça ser retomado, mas deixemos isto para o final.

É neste espaço de confluência entre o político e o jurídico que percebemos o emergir de um fenômeno denominado judicialização da política. Poderíamos afirmar que se trata de uma nova perspectiva do direito frente à política. Representa um fenômeno polifacético com profundas e importantes implicações na estrutura do Estado, na produção do direito e no exercício de Poder.

Demonizado por alguns e considerada como postura revolucionária por outros, a judicialização da política é o tema central deste artigo.

Nossa proposta é identificar e analisar seus contornos, nos aproximando de suas bases teóricas para, a partir das posturas que refutam sua presença nos Estados Democráticos, traçar possíveis caminhos rumo à reconstrução de uma relação dialógica entre os Poderes.

Para alcançar os objetivos propostos, realizamos uma revisão crítica da literatura e analisamos alguns posicionamentos da jurisprudência, não só de nosso Tribunal Constitucional, mas também de outros tribunais em outros países.

\section{UMA APROXIMAÇÃO AO TEMA}

De modo geral, o termo "política" sempre veio carregado pelo peso do poder. Ao qualificar o termo "judicialização" pela forma "política", ocorre, necessariamente, a partir da perspectiva de alguns teóricos, uma mudança no exercício desse poder. O Judiciário passa a ocupar um papel de destaque na tomada de decisões frente aos demais Poderes do Estado, especialmente no que concerne às políticas públicas e à proteção de direitos fundamentais.

Como bem nos sinaliza Comaille (1999) a

[...] judicialização é um termo utilizado para designar o que seria a extensão do rol da Justiça, como instituição, no tratamento dos 
"problemas da sociedade" entre eles alguns políticos, para os quais a Justiça não havia sido convocada anteriormente ou sobre os quais ela não previa intervir.

Para Brandão (2011) estamos diante de um

[...] processo pelo qual as Cortes e os juízes passam a dominar progressivamente a produção de políticas públicas e de normas que antes vinham sendo decididas (ou, como é amplamente aceito, que devem ser decididas) por outros departamentos estatais, especialmente o Legislativo e o Executivo.

Esse prisma dinâmico do fenômeno da judicialização da política retrata bem uma de suas características: a de estar em constante construção. Assim, a judicialização da política ao longo da história ganhou matizes diferentes mesmo tratando-se de um mesmo acontecimento.

Nestes termos, podemos entender a judicialização da política como um processo que foi acontecendo por etapas. A primeira fase se deu como judicial review of legislation norteamericano no emblemático caso Marbury v. Madison $(1803)^{2}$; a segunda fase é percebida logo após a Segunda Guerra Mundial com a redemocratização de alguns países (Italia e Alemanha) e a independência de algumas colônias (alguns países africanos e a India); a terceira fase foi marcada pelo fim de ditaduras militares e pelo início de processos de redemocratização na América Latina assim como pela transição de regimes comunistas para regimes capitalistas no Leste Europeu.

Percebe-se, como bem salientou Tate (1995) em seus estudos, que se trata de um evento que transborda as fronteiras nacionais. A expansão global do Poder Judiciário representa um acontecimento de nossa Era que pode ser caracterizado por diferentes posturas. Desse modo, Hirschl (2007) elenca as diferentes formas como a judicialização da política pode se manifestar. Assim, de forma sistematizada, o fenômeno se evidenciaria quando ocorrer: (a) a transferência de prerrogativas tradicionais dos Poderes Legislativo e Executivo ao Judiciário; (b) corroboração judicial das mudanças de regime; (c) a fiscalização do processo democrático; (d) justiça restaurativa e (e) questões de teor puramente político cuja solução é historicamente

\footnotetext{
${ }^{2}$ Foi neste caso que, pela primeira vez, a Suprema Corte Norteamericana declarou a inconstitucionalidade de lei mesmo diante do silêncio da Constituição.
} 
delegada ao campo político como por exemplo questões étnicas, linguísticas e religiosas em sociedades com profundas divisões.

Exemplos da expansão do Judiciário são facilmente encontrados no cenário brasileiro. Há bem pouco tempo, tivemos o Supremo Tribunal Federal manifestando-se sobre o controle judicial em casos de impeachment ${ }^{3}$ (no caso da ex-presidente Dilma Roussef, afastada no dia 31 de agosto). Tivemos, também, os casos de ação penal contra membros do Congresso Nacional envolvidos no escândalo do "mensalão"4; o reconhecimento de união estável em relações homoafetivos ${ }^{5}$ e a deliberação sobre a tipicidade nos abortos de fetos anencéfalos ${ }^{6}$.

No cenário internacional podemos citar, como exemplos, o pronunciamento do Tribunal Constitucional Espanhol sobre o manifesto independentista da província da Catalunha; na África do Sul, a Suprema Corte julgou constitucional a anistia para os que confessassem crimes cometidos durante o apartheid - Azapo Case, 1996; na Argentina, a Suprema Corte julgou constitucional o chamado "corralito"7 entre outros casos.

Os casos citados correspondem a exemplos de como as funções dentro de um Estado legislar, julgar e executar - podem se entremesclar causando tensões entre os Poderes. $\mathrm{O}$ jurídico e o político convergem numa trama perigosa que, a depender da conjuntura em que se apresente, poderá colocar em jogo o próprio Estado Democrático de Direito.

Para melhor compreender a judicialização da política, é imprescindível que nos debrucemos sobre as teorias que lhe servem de suporte com vistas a averiguar, nelas, seus traços primordiais. Neste sentido se direcionam as próximas linhas.

\section{O FENÔMENO E SUAS TEORIAS}

A presença da judicialização da política, como bem frisamos no epígrafe anterior, é uma prática comum e acarreta calorosos debates e posicionamentos antagônicos. Certo é que estamos falando de tema que se entrelaça com nosso sistema democrático e que, a depender dos argumentos levantados, pode reforçá-lo ou colocá-lo em jogo.

\footnotetext{
3 Caso Collor de Melo STF, MS 21.564, MS 21.689-1, DJ, 27-8-199; Caso Dilma Roussef STF MS 34371

4 STF, Ação Penal no 470.

5 Ação Direta de Inconstitucionalidade (ADI) 4277 e a Arguição de Descumprimento de Preceito Fundamental (ADPF) 132

6 STF, ADPF 54

7 A economia argentina passou a ter, como única referência monetária, o peso argentino (2004)
} 
Ao alçar o cenário de decisões políticas do âmbito do Legislativo ou por vezes do Executivo, para o palco do Poder Judiciário, juízes e tribunais passam a assumir a condição de agentes políticos do Estado, inclusive implementando suas decisões.

Uma das possíveis condições para a existência deste novo palco das decisões políticas, pode ser encontrada no elevado desgaste e custo político do parlamentar ao tomar uma determinada posição. Como consequência desse mecanismo de autoproteção, a análise do custo/benefício feito pelos legisladores pode obedecer a critérios bem diferentes da proteção do interesse e das necessidades dos cidadãos. Enquanto na dimensão política prevaleceria o princípio da oportunidade política e o da legitimidade democrática, na esfera judicial prevaleceria o princípio da legalidade e o da legitimidade técnica.

No que se refere às teorias que dão suporte à judicialização da política, encontramo-nos com a dificuldade de sua sistematização. Primeiro, por tratar-se de fenômeno multidisciplinar, o que poderá ser abordado tanto por juristas, como por sociólogos e cientistas políticos, de modo que cada uma dessas abordagens terá os contornos típicos de sua matéria, pluralizando as perspectivas, é verdade, mas dificultando a sistematização. Por outro lado, em cada país, há processos constitucionais diferentes, e tal diversidade de cenários representa um complicador do mesmo modo, já que as particularidades presentes em determinado país ou região tornam o evento muito próprio, muito único. Outrossim, determinada característica essencial em determinada abordagem teórica pode estar presente, em menor expressão, em outra teoria.

Não obstante, mesmo diante das dificuldades em se apresentar as teorias sobre a Judicialização da Política, é primordial que superemos essa fase já que é, na teoria, que encontraremos os alicerces que suportam todo o arcabouço sobre o tema em estudo.

Feitas essas digressões, passemos às teorias. Podemos dizer que as teses que tratam do tema são, para fins didáticos, agrupadas em teorias Conceitualistas, Funcionalistas e Estratégicas.

Trataremos, primeiro, das Teorias ditas Conceitualistas. Com o fim da Segunda Guerra Mundial e a positivação de direitos nas Constituições dos Estados, demos os primeiros passos no processo de constitucionalização dos direitos e, com isso, obtivemos uma ampliação dos poderes do Judiciário.

Ao mesmo tempo, o magistrado passa a gozar de garantias que permitem uma maior liberdade deliberativa, livres das amarras de outro "poder controlador" sobre o teor de suas decisões. 
Esta ampliação do papel do Judiciário foi proporcionada, entre outros fatores, por um novo desenho de Constituição e pelo modo como esta se operacionaliza na prática cotidiana. A Constituição passa de um documento que trata da arquitetura do Estado, com seus Poderes e competências para ser compreendida como instrumento de conteúdo de alto nível normativo, dotada de objetivos e finalidades a serem alcançados.

As Constituições passam a ter novos conteúdos, um conjunto de direitos com força ativa, impondo tarefas, as quais devem ser efetivamente realizadas, sejam de ação ou de abstenção, orientando a própria conduta Estatal como um todo (Hesse, 1991, p. 19). Além disso, as Constituições modernas passaram a dotar algum tipo de controle de constitucionalidade, seja por intermédio de um tribunal específico, ou de forma diluída pelo Poder Judiciário, com o objetivo de traduzir as disposições constitucionais, atribuindo-lhes praticidade no cotidiano público. (Hirschl, 2012, p. 27).

O movimento mais próximo de nós na história e no qual nos encontramos, é o Neoconstitucionalismo, que representa uma revalorização da Constituição e tem suas raízes numa concepção pós-positivista. Suas características concorrem para este novo perfil do Poder Judiciário. Como bem apontado pelo professor Humberto Ávila da Universidade de São Paulo, no Neoconstitucionalismo podemos destacar quatro fundamentos que propõem uma mudança significativa nas bases da Teoria Constitucional Clássica. São mudanças que se referem, no âmbito normativo, "da regra ao princípio; no metodológico da subsanação à ponderação; no axiológico, da justiça geral à justiça do caso particular e no âmbito organizacional, do Poder Legislativo ao Judiciário.” (Ávila, 2009, p.03). Com base nisto, podemos afirmar que o Neoconstitucionalismo possui, como um de seus pilares, o reclamo de uma prática jurisdicional diferenciada mais ampla, isto em função, talvez, de possuir os valores como pauta interpretativa, o que implicaria em uma maior elasticidade na atuação do magistrado.

Há Conceitualistas que apontam, como característica, a de que a judicialização da política é fruto da tensão existente entre Executivo e Legislativo. Indicam a crise do final da década de 1970 como marco histórico em que se proporcionaram importantes mudanças nas prestações sociais dadas pelo Estado. Vivenciava-se a primeira crise do estado de bem-estar social. No entanto, mesmo diante da escassez e necessidade de cortes econômicos, permitiu-se novas vias de acesso aos direitos. A judicialização é aporte de acesso para determinados grupos que tiveram seus direitos limitados pelas profundas limitações exigidas pelo momento histórico vivido (Shapiro, 1999). 
Por outro lado, temos as teorias Funcionalistas, para quem a judicialização da política decorre da necessidade de um Poder neutro que solucione os problemas entre os demais Poderes ou entre os Estados-membros e a União. O federalismo e os sistemas presidencialistas são apontados como terrenos férteis onde a judicialização da política pode se propagar com maior velocidade.

Nos Estados em que há atuação das agências reguladoras no sistema de descentralização administrativa (com forte tendência nos Estados liberais, com ampla privatização), o Judiciário é acionado a intervir, seja nos litígios de coordenação entre elas, seja nas lides entre elas e os cidadãos ou, ainda, nos conflitos de competência destas com outros órgãos integrantes da estrutura do Estado (Hirschl, 2012, p. 30).

Brandão (2013) salienta ainda que novas teorias têm surgido, deslocando o foco de preocupação, motivadas por entender os interesses dos grupos de poder que toleram a expansão do Judiciário em áreas que teoricamente fugiriam à sua competência. Em suas palavras:

O foco, portanto, não mais se coloca em uma cultura de direitos ou em um arranjo institucional caracterizado pela forte divisão do poder, mas na atuação estratégica de grupos politicamente relevantes (daí tais concepções poderem ser agrupadas sob o rótulo de "teorias estratégicas"). Enfim, desloca-se a atenção da ideologia e da estrutura do sistema político para os interesses de grupos políticos e para os conflitos sociais, econômicos e políticos concretamente existentes em uma comunidade estatal. (Brandão, 2013 p. 10)

Um dos grandes expoentes que seguem esta linha de raciocínio é Ginsburg (2003). Em sua obra, ele assevera que haveria uma relação de proporcionalidade entre o incentivo ao avanço do Poder Judiciário e os riscos de determinados grupos políticos não se elegerem. Para ele, quando determinado grupo político não tem a certeza de vencer as eleições, deposita, no Poder Judiciário, a função de proteger um núcleo mínimo de interesses e valores que com eles se afinam. Neste sentido, democracia e judicialização da política correspondem a conceitos que andam de mãos dadas e em paralelo. Podemos afirmar, assim, que esses grupos políticos continuam no cenário, seja realizando ações de pressão, seja propondo ações judiciais. 
Do ponto de vista do processo político como um todo, a judicialização da política contribui para o surgimento de um padrão de interação entre os Poderes (epitomizado no conflito entre tribunais constitucionais e o Legislativo ou Executivo), que não é necessariamente deletério à democracia. A ideia é, ao contrário, que a democracia constitui um requisito da expansão do poder judicial. Neste sentido, a transformação da jurisdição constitucional em parte integrante do processo de formulação de políticas públicas deve ser visto como um desdobramento das democracias contemporâneas. (Castro, 1997)

Destarte, ao constitucionalizar questões políticas, os grupos políticos não eleitos continuariam protegendo e lutando por seus interesses no Judiciário. No entanto, a equalização entre democracia e judicialização da política de acordo com Hirschl parece não seguir essa ordem. Por traz de uma aparente democratização dos Estados, com uma ampliação do sufrágio eleitoral, e uma deliberação majoritária no Parlamento que melhor representaria a sociedade, haveria uma trama engendrada pelas elites no sentido de alterar o campo deliberativo. $\mathrm{O}$ Judiciário, pressionado pelas elites dominantes, protegeriam, nesta arena, direitos e interesses a eles relevantes.

São suas as reflexões:

Especificamente, eu sugiro que o aumento do poder das Cortes através da constitucionalização é mais bem entendido como um produto da interação estratégica entre três grupos-chave: elites políticas ameaçadas, que tentam preservar ou aumentar sua hegemonia por meio do insulamento do poder de elaborar políticas públicas em geral, e, em particular, do insulamento das suas preferências políticas, das vicissitudes do processo democrático, enquanto elas professam seu apoio à democracia; elites econômicas, que consideram a constitucionalização de direitos, especialmente da propriedade e demais liberdades econômicas, como mecanismos que estabelecem limites à ação governamental e uma agenda favorável ao mercado e aos negócios; elites judiciais e Supremas Cortes, que buscam aumentar sua influência política e reputação internacional. (HIRSCHL, 2008, p. 39) 
A partir do nosso ponto de vista, a perspectiva de Tom Ginsburg é facilmente percebida em democracias recentes como a brasileira ou em Estados com alta pluralidade de grupos sociais como Espanha e suas muitas Comunidades Autônomas.

Expostas as teorias que buscam dar base à judicialização da política, demarcaremos os contornos de outro fenômeno que com ele se afina mas que dele se diferencia. Referimo-nos ao ativismo judicial.

\section{O ATIVISMO JUDICIAL}

A judicialização da política vem de mãos dadas com outro acontecimento também contemporâneo: o ativismo judicial. Conceituar ativismo judicial representa tarefa árdua já que, para fazê-lo, o intérprete deve adotar, necessariamente, uma postura ideológica em relação ao objeto em discussão. Ao adotar uma postura ativa o magistrado ou tribunal irremediavelmente adota um posicionamento político. Assim sendo, ativismo judicial e judicialização da política representam fios de uma mesma trama.

Trata-se de postura assumida pelo magistrado que está comprometida com a efetivação dos direitos por meio de uma interpretação mais materializada dos ditames constitucionais. Ao compreender o carácter normativo da Constituição, o magistrado instrumentalizaria a realização de seus preceitos tornando-se coautor na efetivação deles.

Os efeitos da postura ativista do magistrado podem ser sentidos, por exemplo, quando da ocorrência da

(i) aplicação direta da constituição a situações não expressamente contempladas no texto e independentemente de manifestação do legislador; (ii) declaração de inconstitucionalidade tendo por base critérios menos rígidos que os de patente e ofensiva violação da Constituição; (iii) a imposição de condutas e abstenções ao Poder Público, especialmente em matéria de políticas públicas. (Barroso, 2009, p.75)

É importante perceber que o Ativismo Judicial é, sobretudo, uma postura e atitude nas escolhas do modus operandi em que se exerce a jurisdição. Analisando o fenômeno, o professor Gomes (2013) relaciona duas espécies de ativismo judicial. O primeiro é chamado de ativismo 
inovador na medida em que o magistrado cria norma jurídica por meio de uma hermenêutica constitucional expansionista. O segundo, denominado de ativismo revelador, também supõe a criação de norma jurídica tendo por base princípios constitucionais ou em função de uma lacuna presente na lei. Esta nova postura criadora e criativa adotada pelo Poder judiciário o posiciona em situação de destaque no cenário atual.

Com o objetivo de distinguir a judicialização da política do ativismo, Barroso (2009, p. 2) sistematiza que o primeiro se instrumentaliza em função do modelo constitucional que se adota, ao passo que o segundo corresponde ao modo como o magistrado interpreta os dispositivos constitucionais.

A judicialização e o ativismo judicial são primos. Vêm, portanto, da mesma família, frequentam os mesmos lugares, mas não têm as mesmas origens. Não são gerados, a rigor, pelas mesmas causas imediatas. A judicialização, no contexto brasileiro, é um fato, uma circunstância que decorre do modelo constitucional que se adotou, e não um exercício deliberado de vontade política. Em todos os casos referidos acima, o Judiciário decidiu porque era o que lhe cabia fazer, sem alternativa. Se uma norma constitucional permite que dela se deduza uma pretensão, subjetiva ou objetiva, ao juiz cabe dela conhecer, decidindo a matéria. Já o ativismo judicial é uma atitude, a escolha de um modo específico e proativo de interpretar a Constituição, expandindo o seu sentido e alcance. Normalmente ele se instala em situações de retração do Poder Legislativo, de certo descolamento entre a classe política e a sociedade civil, impedindo que as demandas sociais sejam atendidas de maneira efetiva. A idéia de ativismo judicial está associada a uma participação mais ampla e intensa do Judiciário na concretização dos valores e fins constitucionais. (Barroso, 2009, p. 02)

Mesmo que o ativismo e a judicialização da política correspondessem a conceitos diferentes, sua aproximação se dá no resultado de suas ações, já que, de um modo ou de outro, as decisões tomadas avançam pelos caminhos que vão além dos delimitados ao Poder Judiciário.

Estabelecidos os contornos do ativismo como elementos que podem ser percebidos na judicialização da política, ocuparemo-nos de analisar dois dos mais fortes argumentos 
contrários à judicialização da política: a legitimidade contramajoritária à mácula da Separação dos Poderes. Em seguida, trataremos de elaborar nossas críticas, buscando traçar um caminho conciliatório e viável para a existência desse fenômeno entre nós que, parece, não retrocederá.

\section{A POSIÇÃO CONTRAMAJORITÁRIA}

Um dos fortes argumentos contrários à judicialização da política corresponde a ser, esta, o fruto de uma posição contramajoritária. Criado por Alexander Bickel, em sua obra The least dangerous branch, a posição contramajoritária postula a tese de que haveria afronta ao sistema democrático quando tribunais ou magistrados invalidassem decisões tomadas pelo Poder Legislativo. O ponto fulcral da postura se baseia em que os membros do Poder Judiciário não são eleitos pelo povo e, neste sentido, não o representam. Não teriam legitimidade, esses magistrados, para modificar as determinações legislativas, portanto.

A pergunta que em seguida nos fazemos é: onde se constata a legitimidade de agir de um tribunal? A resposta a essa indagação pode ser dada a partir de muitos prismas. O primeiro, e que nos parece o mais palpável deles, é que estamos falando de uma atribuição estabelecida na própria Constituição por uma Assembleia Nacional Constituinte. Este argumento nos leva ao entendimento de uma legitimidade formal; no entanto, é preciso ir além. É necessário questionarmos o valor das decisões majoritárias. Seriam as decisões tomadas por uma maioria mais justas que aquela tomada por um número inferior de pessoas? (Rawls, 2002)

A atuação do magistrado está pautada por limites e propósitos a serem alcançados. Sua atuação deve, em tese, encaminhar-se neste sentido. Por este motivo, suas decisões, mesmo quando contrariam possíveis posições “dominantes”, devem nortear-se pelas disposições que a Constituição estabelece às quais este, o Poder judiciário, deve respeito. Temos exemplos, ao longo de nossa história, de como coletivos subjulgaram minorias, afastaram direitos sob o pretexto de decisões tomadas pela maioria ${ }^{8}$. Por este prisma, podemos afirmar que a presença de controle político pelo Judiciário é medida democrática já que permite uma equalização das forças, ao conferir voz às minorias. Dworkin assim se posiciona ao afirmar que:

Se os tribunais tomam a proteção de direitos individuais como sua responsabilidade especial, então as minorias ganharão em poder

\footnotetext{
${ }^{8}$ O Holocausto e a retirada de direitos de judeus e outras minorias éticas pode ser citado como exemplo.
} 
político, na medida em que o acesso aos tribunais é efetivamente possível e na medida em que as decisões dos tribunais sobre seus direitos são efetivamente fundamentadas. (Dworkin, 2001, p. 26)

Entretanto, a postura adotada por Dworkin não é a de que toda e qualquer questão deve ser deliberada pelo Juiz. Haverá temas que, por seu alto teor político, devem ser conduzidos pelo Parlamento.

Hércules não é um ativista. Ele vai recusar-se a substituir seu julgamento por aquele do legislador quando acreditar que a questão em jogo é fundamentalmente de política, e não de princípio, quando o argumento for sobre as melhores estratégias para satisfazer inteiramente o interesse coletivo por meio de metas, tais como a prosperidade, a erradicação da pobreza ou o correto equilíbrio entre economia e preservação. (Dworkin, 2001)

Desse modo, podemos afirmar que o Judiciário é uma via de acesso ao direito por parte das minorias. Diante disto, não se trata de via de excelência já que cabe, prima facie, ao Poder Legislativo, deliberar sobre tais questões de conteúdo essencialmente político. No entanto, vale ressaltar o carácter democrático que adquire a judicialização da política quando percebida por este viés.

\section{DA SEPARAÇÃO DOS PODERES E SUA NECESSÁRIA RELEITURA}

Antes de tecer alguns comentários no epígrafe que se segue, achamos conveniente fazer um alerta que nos parece dos mais pertinentes e necessários. Toda e qualquer teoria, ideia ou tese deve ser analisada e compreendida tendo em vista o contexto em que foi elaborada. São estas as variáveis de temperatura e pressão que servem como pressupostos indispensáveis às ilações que surgem como resultado. Assim, e levando em consideração esta premissa, ao explorar a separação dos Poderes/Deveres do Estado devemos, impreterivelmente, assimilar seu marco histórico para, em um segundo momento, enfrentarmos seu marco teórico, o que nos permitirá compreender, adequadamente, as ideias daqueles que o idealizaram.

Pois bem, voltemos ao tema examinando as origens da Separação dos Poderes. 
Aristóteles, após estudar 158 constituições do mundo helenístico, chega à conclusão de que o governo da cidade seria mais eficiente se ocorresse a divisão de funções exercidas pelo poder soberano da cidade. Foi da semente plantada por Aristóteles em sua obra Politekón, escrito no século III a.C., que deu as bases teóricas para a compreensão do instituto da Separação dos Poderes.

Vale salientar que a Grécia contemporânea de Aristóteles tinha, como característica, a autonomia das cidades-estado, cujo ponto em comum é a formação societária hierarquizada e estratificada. $\mathrm{O}$ modo de deliberação dos temas relevantes, desde a perspectiva aristotélica, leva em consideração a condição de cidadão, qualidade não ostentada por todos os membros da sociedade e que permitia a participação nas discussões. A participação do cidadão o aproximaria o governo, dando os contornos da democracia grega.

O discurso Aristotélico permitiu que a partir dele outros teóricos desenvolvessem novas perspectivas sobre o tema. Por conseguinte, devemos discorrer sobre outro importante filosofo e teórico, a saber, Montesquieu.

A aparente preocupação em dividir funções, parece ser o ponto em comum entre os pontos de vista de Aristóteles e Montesquieu. No entanto, temos muito mais que separa as duas concepções. Temos um contexto diferente, óticas distintas.

Ao escrever sua obra $O$ Espírito das Leis, o Barão de Montesquieu vivenciava um outro cenário que o empurrou na direção de novas reflexões. Tempo e espaço colaboraram com outros tons dados à Separação dos Poderes. Vivia-se no século XVIII, período pré-revolucionário na França que foi marcado pelo Absolutismo Monárquico. Deste modo, neste magma, surge a postura adotada por Montesquieu: a de ruptura com a centralização dos Poderes nas mãos do monarca.

Como ponto curioso a ser apontado, percebe-se que a filosofia de Aristóteles, pautada na busca incessante pela felicidade, confere, ao indivíduo um perfil otimista no que se refere a sua natureza e relação com o Dever Público. O mesmo não ocorre com Montesquieu que, de modo antecipado desconfia do homem que por sua natureza, teria uma tendência à arbitrariedade.

Voltando para as ideias de Montesquieu, temos como consequência que o Poder de Julgar foi remodelado, atribuindo-se, ao Poder Judiciário, a máxima neutralidade no exercícios de suas funções jurisdicionais. A atuação do magistrado se pauta na estrita legalidade, o que levaria à preservação da tão ansiada segurança jurídica. 
Ocorre que as ideias de uma suposta separação total entre os Poderes/Deveres do Estado proposta por Montesquieu parece ser, para alguns doutrinadores, uma má interpretação de sua doutrina. Neste sentido, tem-se o consistente posicionamento de Arcaya (1996, p. 345).

La teoría de la separación de poderes ha sido interpretada de distintos modos. Una de las versiones más radicales sostiene que Montesquieu atribuye las tres funciones esenciales del Estado a órganos conformados por autoridades individuales o colegiadascompletamente distintos e independientes entre sí. Esas funciones, en consecuencia, estarían completamente separadas. Y esta radical separación sería funcional, personal y material: cada órgano ejercería la totalidad de una función — legislativa, ejecutiva o judicial— en forma plenamente independiente y monopólica; ninguna autoridad podría revocar las decisiones de las otras; y a todas les estaria prohibida cualquier relación o comunicación entre ellas. Sin embargo, esa interpretación extrema, además de inaplicable a la realidad, no parece desprenderse de los textos de Montesquieu. Pues, si analizamos el famoso capítulo sexto del libro XI, que trata acerca de la monarquía inglesa, nos encontramos con un cuadro diferente. Un punto crucial de la argumentación de Montesquieu es que la separación de poderes no es total o absoluta, sino relativa.

Há riscos em se compreender uma Separação dos Poderes a partir de uma perspectiva de cisão total entre eles. Neste sentido, e dando um salto na História mas alinhavando as ideias, Ackerman (2005), ao relacionar as teorias funcionalistas e consequentemente uma maior expansão do judiciário com sua presença em Estados Federados bem como em Estados com alto grau de Separação entre os Poderes. Para ele:

[...]assim como a criação de poderes independentes no centro e na periferia aumenta a necessidade funcional de um juiz relativamente imparcial coordenar a dinâmica de interação institucional, o mesmo acontece com a criação de um Presidente poderoso e de um Legislativo independente" 
Entendemos a Separação dos Poderes do Estado como tentáculos de um mesmo corpo que, embora articulados de modo independente, provêm de um tronco comum, a sociedade que lhe dá vida. Neste sentido, seus movimentos são guiados em prol do bem-comum, devendo existir nele uma necessária sinergia.

Desta forma, a Separação dos Poderes deve ser entendida a partir de uma perspectiva plástica e flexível, permitindo, a cada um dos Poderes, uma legítima expansão de suas competências.

A existência de hiatos proporcionados pelo legislador que permitem a existência de "zonas em branco" - desprovidas de normatização - representam verdadeiras renúncias de competência que, em não poucas ocasiões, deixam à intempérie direitos fundamentais para o exercício da cidadania. Por conseguinte, dar-se-ia uma "licença" para os demais Poderes e, nesse sentido, parece-nos plausível falar não em expansão de um Poder sobre o outro mas no exercício legítimo de suas funções. No entanto, também resulta importante ressaltar que este tipo de postura só poderia ser realizada em situações excecionais, quando se constata o mal funcionamento da própria política. Ou seja, não nos parece salutar uma hipertrofia do papel dos tribunais em uma democracia. O risco de uma "ditadura de toga" levada pela mão das ideias de uma exclusiva e final palavra sobre a Constituição deve ser evitado.

Vivemos tempos difíceis no Brasil. O elevado índice de conflitividade tem aumentado, a passos largos, o número de questões controversas com elevado conteúdo político. O que deveria ser uma atividade residual e complementar do Poder judiciário tem se convertido em atuação permanente e etapa necessária. A judicialização da política em nosso país adquire números alarmantes.

Parece-nos, então, inafastável o dever de se refletir sobre novos modelos, novas formas de relacionamento entre os Poderes que permitam um reequilíbrio entre eles. O diálogo institucional parece ser o caminho a ser perseguido rumo ao entendimento de que cada um dos Poderes, na medida de suas funções, possuem finalidades e objetivos comuns. Isto pressupõe que, embora cada um dos Poderes possua seu rol de competências, poderá ocorrer, em determinado momento histórico, um intercâmbio entre eles, uma colaboração para a efetivação dos propósitos demarcados na Constituição.

Tendo em mente essa hipótese, trataremos de analisar as possibilidades de um diálogo institucional, averiguando sua viabilidade e benefícios democráticos. 


\section{EM BUSCA DE DIÁLOGO}

As doutrina canadense e norteamericana posicionaram as discussões sobre a judicialização da política a partir de um novo ponto de vista: o da busca de uma teoria construída, não preocupada em definir a legitimidade do Judiciário para decidir questões políticas mas, sim, encaminhada na direção da decisão cooperada.

A proposta é conceber as decisões a partir de uma perspectiva dialógica em que o ouvir e o falar façam parte do discurso e que os argumentos e contra-argumentos sejam os motores para a edificação da melhor medida a ser adotada.

Resulta importante frisar que a ideia de diálogo talvez leve o leitor a conceber uma ideia um tanto quanto romântica do que realmente acontece. Mendes C. (2008), um dos defensores desta doutrina, assim se posiciona sobre o uso do termo:

\footnotetext{
“diálogo" seria um termo inadequado para caracterizar a interação, uma visão cor-derosa e distorcida que esconderia a dimensão do conflito entre os poderes. Conforme tal crítica, os poderes não estariam conversando, ou respeitosamente dialogando, mas brigando, disputando espaços etc. Eu acho que essa objeção é plausível, mas meramente terminológica. Talvez a palavra diálogo não seja, mesmo, a melhor. Acredito que ela conserve, porém, um ideal normativo interessante, que destaca a relevância de que os poderes levem os respectivos argumentos a sério, de que tentem se engajar num tipo de comunicação que não se confunda com uma mera disputa adversarial, ou com uma conversa de surdos, na qual somente falam, mas não escutam. (Mendes, 2008)
}

Assim, o que pretende a Teoria do Diálogo Institucional é focalizar a adoção de medidas e decisões onde a pluralidade de interlocutores seja a nota distintiva. Esta característica se coloca diametralmente oposta à noção de isolamento entre os Poderes. Dixon (2011) propõe "a transformação do discurso dos direitos constitucionais de um monólogo judicial em um rico e mais equilibrado diálogo interinstitucional, que reduz, se não elimina, a tensão entre a proteção judicial dos direitos fundamentais e a tomada de decisão democrática” 
Ou seja, a partir desta perspectiva, pouco importa o alcance que deve ter o papel do Judiciário, já que ele não será o único a "falar" sobre o tema em questão. A participação ativa dos demais Poderes levaria, inclusive, a uma corresponsabilização quanto aos resultados obtidos, fruto deste diálogo.

A dinâmica resultante proporcionaria, ademais, um aperfeiçoamento do equilíbrio salutar que deve existir entre os Poderes dentro de um Estado. A interpretação constitucional passa a ser legítima quando decorre dessa parceria.

Conciliar valores tão díspares em uma sociedade cada vez mais plural, como é o caso da brasileira, por exemplo, representa um estorvo. No entanto, entendemos tratar-se da via mais adequada, frente à Democracia e ao próprio Estado democrático de Direito.

\section{8 ÚLTIMAS COSIDERAÇÕES}

Como bem constatou Tocqueville (1977), dificilmente haverá uma controvérsia moral e política que também não se torne uma controvérsia judicial. Sua afirmação continua contendo o mesmo colorido na atualidade.

Questões políticas e jurídicas se entremesclam no cenário democrático e o que, a priori, pode parecer uma mácula, nada mais é que o fruto desse equilíbrio dinâmico característico das sociedades democráticas. A Judicialização da Política corresponde ao "risco calculado" que possibilita compreender a pluralidade de vozes existentes numa comunidade.

A comunicação que poderia ocorrer entre os Poderes proporcionaria não um deslocamento do núcleo de deliberação de questões políticas, mas a circulação entre os Poderes dessas questões.

É importante que voltemos a velhos conceitos. A democracia é, por definição plural, fruto do diálogo e é este mesmo diálogo que deve ser elemento primordial para a estruturação da relação entre os distintos Poderes do Estado. Pensemos, pois, em estruturar instrumentos aptos a proporcionar um ambiente favorável à discussão construtiva, que não esbarre na burocracia que diminui as possibilidades de ganho.

Uma discussão entre iguais, entre Poderes Iguais que guardam entre si uma função comum: são todos eles, Legislativo, Executivo e Judiciário, guardiões dos valores, fundamentos e objetivos estabelecidos por nossa Constituição. 


\section{REFERÊNCIAS}

ACKERMAN, Bruce. The failure of the founding fathers: Jefferson, Marshall and the rise of presidential democracy. Cambridge: The Belknap Press of Harvard University Press, 2005 p. 14

ARCAYA, Oscar Godoy. Antología Política de Montesquieu. Revista Estudios Públicos, otoño, 1996. p. 345.

BARROSO, Luis Roberto. Judicialização, Ativismo Judicial e Legitimidade Democrática. Revista Atualidades Jurídicas - Revista Eletrônica do Conselho Federal da OAB. Ed. 4. Janeiro/Fevereiro 2009. Disponível em: <http://www.plataformademocratica.org/Publicacoes/ 12685_Cached.pdf>. Acesso em: 10 out. 2016.

BRANDÃO, Rodrigo. A judicialização da política: teorias, condições e o caso brasileiro. Disponível em: <http://docplayer.com.br/9313034-A-judicializacao-da-politica-teorias-condicoese-o-caso-brasileiro.html. Acesso em: 05 agosto 2016.

CASTRO, Marcus Faro de. O Supremo Tribunal Federal e a Judicialização da Política. Revista Brasileira de Ciências Sociais. São Paulo, v.12, n.34, p.147-156, 1997. Disponível em: $<$ http://portal.anpocs.org/portal/index.php?option=com_docman\&task=doc_view\&gid= 5342\&Itemid=361>. Acesso em $1^{\circ}$ set. 2016.

COMMAILLE, Jacques. Normes juridiques et régulation sociale. Retour à la sociologie générale. In: __ _ CHAZEL, François (Dir.). Normes juridiques et régulation sociale. Paris: LGDJ, 1991. p. 13-22.

DWORKIN, Ronald. O Império do Direito. Trad. Jefferson Luiz Camargo. São Paulo: Martins Fontes, 1999.

Uma Questão de Princípio. Trad. Luís Carlos Borges. São Paulo: Martins Fontes, 2001. 
GINSBURG, Tom. Judicial Review in new Democracies: Constitucional Courts in Asian Cases. University of Illinois. Cambridge - University Press. 2003. Disponível em: <http://catdir.loc.gov/catdir/samples/cam033/2002041004.pdf>. Acesso em: 2 de setembro de 2016.

HESSE, Konrad. A força normativa da Constituição. Trad. Gilmar Ferreira Mendes. Porto Alegre: Sergio Antonio Fabris, 1991.

HIRSCHL, Ran. Towards juristocracy: the origins and consequences of the new constitutionalism. Cambridge: Harvard University Press, 2007. p. 124/129.

HIRSCHL, Ran. The judicialization of politics. In: WHITTINGTON, Keith; KELEMEN, R. Daniel; CALDEIRA, Gregory A. The Oxford handbook of law and politics. Nova York: Oxford University Press, 2008. P. 39-40.

HIRSCHL, Ran. A judicialização da megapolítica e o surgimento dos tribunais políticos. In: MOREIRA, Luiz (Org). Judicialização da Política. São Paulo: 22 Editorial, 2012.

MCCANN, Michael. "How does Law Matter for Social Movements?" en Garth, Bryant and Sarat, Austin How does Law Matter? (Northwestern University Press, 1998), p.81.

MENDES, Conrado Hübner. O STF no jogo da separação de poderes: tensões e ajustes. SBDP - Sociedade Brasileira de Direito Público. 2008. Disponível em: <http://www.sbdp.org.br/ observatorio_ver.php?idConteudo=12>. Acesso em: 02 set. 2016.

MENDES, Gilmar Ferreira; COELHO, Inocêncio Mártires; BRANCO, Paulo Gustavo Gonet. Curso de direito constitucional. 2. ed. São Paulo: Saraiva, 2008.

NUNES JÚNIOR, Amandino Teixeira. A Constituição de 1988 e a judicialização da política no Brasil. Revista de Informação Legislativa. v. 45, n. 178, p. 157-179, abr./jun. 2008.

SARMENTO, Daniel. A eficácia temporal das decisões no controle de constitucionalidade. In: SARMENTO, Daniel (Org.). O controle de constitucionalidade e a Lei n. 9.868/1999. Rio de Janeiro: Lumen Juris, 2001. p. 101-139. 
SHAPIRO, Martin. The success of judicial review. In: KENNEY, Sally J.; REISINGER, William M.; REITZ, John C. (Ed.). Constitutional dialogues in comparative perspective. Nova York: St. Martin Press, 1999. p. 193-220.

TATE, C. Neal; TORBJÖRN, Vallinder. The global expansion of judicial power. Nova York: New York University Press, 1995.

TOCQUEVILlE, Alexis de. A democracia na América. 2. ed. Belo Horizonte: Itatiaia; São Paulo: Ed. Universidade de São Paulo, 1977. 